\title{
Investigating the Role of Talent Management System (TMS) in the Human Resources Management
}

\author{
Dr. Seyyed Akbar Nilipour Tabatabaei \\ Faculty Member and the Head of the Management Research Institute, \\ ShakhesPajouh Research Center, University of Isfahan
}

MalekMami

PhD student of Human Resources Management, ShakhesPajouh Research Center University of Isfahan

Email: mami.m1367@gmail.com

Doi:10.5296/ijhrs.v5i4.8637 URL: http://dx.doi.org/10.5296/ijhrs.v5i4.8637

\begin{abstract}
The aim of the present article is to investigate the status of talent management in human resources management and how to apply it in attracting and training effective and talented staff. In fact, the aim is to know that how one can utilize it in the best way in organizations and what processes and domains it contains. In the present article, talent management is defined as a system for identifying, employing, training, enhancing, and retaining talented individuals with the objective of optimizing the abilities of organizations for realizing the results with the maximum of productivity. It can be found out that the issues related to talent management can be established in all processes of human resources management. The present research is a descriptive-analytical one. The data collection institute in the present study was note taking. Findings of the present study indicated that the talent management is the main core of HRM and the main factor of success of organizations. Therefore, it can be claimed that talent management plays a sensitive role in the HRM system and accordingly, it seems that the major attention of organizations in doing talent management should be training successors in organizations. Talent management requires the serious determination and comprehensive support of human resources and managers of organizations in order to be able to have deep and solving effects on the processes of HRM.
\end{abstract}

Keywords: Talent management, training the staff, HRM. 


\section{Introduction}

Nowadays organizations have well understood that to obtain success in the complicated global economy and also survival in the competitive environment of business, they need the best talents. Concurrent to understanding the need to employment, development and maintenance of talents, organizations have found out that talents are critical resources which need management to obtain the best results. From 60's to 70's, personnel departments had the responsibility of talent management as a marginal responsibility, while nowadays, talent management has been considered as an organizational duty whose responsibility is burdened on the shoulders of all departments more seriously. Doubtlessly, the present age is the age of organizations and the authorities of these organizations are humans who can produce advancement, movement, and development in organizations as a result of having the most tremendous resources of power, i.e. thought. In recent years, in Iranian organizations, the issue of training and developing human resources in different forms such as identifying and training talents, training successors, future managers, shadow managers, and etc. has been considered (Sayyadi et al., 2012: 82). The third millennium organizations of today refer to "human capital" and "knowledge-based human". Development and growth of human resources in organizations have been considered as the most important resources of production and the key of the survival of firms. The most important challenge in the domain of business is not the issue of technology any longer, but it is more productivity and utilization of talented human resources and human capital and are the main keys of encountering challenges and damages of business in such a way that in recent years, intellectuals and scholars of management speak of a concept called talent management (Shayemi et al. 2013).

During recent fifty years, the social, cultural, economic, and industrial conditions of the world have been faced with so many upheavals and changes which hardly one can find any similarity between the structure of organizations in present time and future. Organizations, as the developed phenomena in the present century, are considered as the real grounds of these upheavals and managers, leaders, and intellectuals of each society or organization are moderators of their multiple directions and their greatest responsibility was to pave the path of the future and at last, obtaining optimal decisions. Future is for those organizations which use all of their own potentialities for encountering new challenges. If we believe that the prerequisite for a developed society is to enjoy developed organizations and developed organizations obtain their power and authority due to the existence of specialized human resources as strategic capitals, it should be accepted that the significance of this valuable and efficient resources in organizations has not been well explained (Ahmadi et al, 2012).

In the present conditions, the most important immediate measure which seems to be done is to create fundamental upheavals based on vision of organizations in the domain of human resources. In other words, organizations should be able to explore opportunities and realize them. The talent management system, by presenting simple and applied plans in the domain of needs assessment of attraction and employment, optimization, motivation, and Maintenance of human resources, and with reliance on the principles of knowledge management, helps organizations (Ahmadi et al., 2012). 


\section{Macrothink \\ International Journal of Human Resource Studies \\ ISSN 2162-3058 \\ 2015, Vol. 5, No. 4}

\section{Definition of the talent management system (TMS)}

Talent management refers to doing a series of integrated activities for guaranteeing attraction, maintenance, motivation, and development of talented staff required for now or the future of organizations.

\section{The history of formation and advent of the TMS}

Since 1981, the concept of the TMS has been organized and unexpectedly, it has increased among managers in such a way that according to the conducted research, about $75 \%$ of superior production, service, and educational organizations utilized the TMS in 2003. The TMS was presented in the Warton Business School under the supervision of University of Pennsylvania for the first time. Warton School had presented the MBA around 80 years ago.

\section{The effects of the TMS in organizations}

The TMS is one of the modern management issues, and currently, it has developed itself as an effective instrument in organizations in line with the development of human capital.

In general, the TMS in organizations includes the following steps:

- Exploring talents required by organizations

- Attracting talents

- Training talents and accelerating their development

- Retaining talents and motivating them sufficiently

General aims pursued in this system are as follows:

- Developing the visions of organizations by senior manager and experts

- Explaining the status quo of organizations using the SWOT matrix.

- Measuring the distance between the status quo and the favorable status in organizations and investigating the need to appropriate human forces in this line and doing necessary educational plans.

\section{Review of literature}

Investigating the review of literature in Iran indicates the attention of researchers to the issue of talent management. These researches are as follows:

1. Industrial Development and Renovation Organization of Iran conducted a plan called the future managers with an approach to talent identification and training successors of managers in the four companies of Iran Khordo, Saipa, Wagon Pars of Arak, and Tabriz Tractor. Indeed this project paid more attention to training successors and had no direct approach to talent management (Rezaeian, as cited in Abulalaei and Ghaffari, 2006).

2. In another article titled as "investigating the status quo and developing indicators of 


\section{MInstitute Macrothink $^{m}$}

talent identification in the field and track sports field", variables such as status quo of talent identification in Iran and the world, the necessity of the existence of models of talent identification was investigated as the most appropriate institution of talent identification and attractor as well as developer (Rezaeian as cited in Alijani, 2002).

3. The title of another article is "evaluating and selecting management talents in the Power Company of Tehran". In this research, interviews and questionnaires were used for determining the necessary characteristics for identification of management jobs in the Power Company. Then, intelligence tests, Edwards' Personality Test, and management skills were employed for evaluating mentioned characteristics. The final result of the research is to select talented individuals for fulfilling management jobs (Rezaeian as cited in Jafari, 2008).

4. The title of another research is "talent management in the oil industry" which investigates the attraction and training of talents in the oil industry with the view of human resources development and ties to present a comprehensive model for talent management in the mentioned industry (Rezaein et al. 2009: 90).

Managers of human resources development are responsible for (at all management levels) the talent management system. Experts of this field are facilitators and advancers of the talent identification system. Nowadays, human resource management and experts are faced with serious questions in their professional fields.

- How can individuals actively and in a future-making way advance their own strategies and those of their organizations?

- How one can have a reservoir of talent in organizations and use it maximally?

- How one can attract and retain the best talents and apply them at the service of staff's and organizations' objectives?

Experts know well that mangers are not born significant, but they obtain greatness and importance with talent management and the system of training successors during their lives. They should be good hunters in the first step, and then, after identifying and exploring talents, expert their efforts for talent training and then talent respecting.

Management levels of organizations have found that nowadays, the value of organizations depends on the quality of the stuff's talents and they increase the value of organizations as rapidly as possible. Investigations done by Barouchloo, the professor of accounting at University of New York in a research conducted in the Brookings Counseling Institute indicate that in 1980, the ratio of visible assets including physical ones and financial savings to invisible assets including patent, brands, and more importantly the staff were averagely $62 \%$ to $38 \%$, while in 1990 , these figures were displaced in the ratio and changed and in 2000 , the value of invisible assets was $85 \%$ and that of visible assets was only $15 \%$. As observed, the significance of organizational talents has increased in these years. It is for several decades that organizations have used the quantitative systems of return on investment and return of assets, but the organizations in $21^{\text {st }}$ century use a new measurement method 
called Reuat adapted from the talent management system. In fact, the talent management system and training successor management refer to a process during which human talents of organizations are identified for taking key positions and jobs in the future and are prepared for taking these jobs via diverse educational planning. Since organizations will face a decreasing competitive challenge in the future and they will need more competent and efficient managers than previous ones; therefore, talent management enjoys more significance in prospective organizations every day (Shayemi et al. 2013).

Steps of the talent management system

Human talents of organizations can be identified with two approaches; firstly, according to potential capabilities, and secondly based on current readiness. After identifying these talents, they should be entered the treasury of human talents of organizations and in the process which takes from 2 to 3 years, they are trained for taking the desired jobs. Performing the talent management plan requires that an organization have a system of evaluating effective and appropriate performance and in fact, it is via the same system that talented individuals with qualification and proficiency can be identified and introduced overtly and covertly. In addition, the organization should have a logical and effective relationship system via which all individuals can advance according to their proficiency. At last, the most important principle in talent management is that managers should enjoy tutoring style. It is in such a case that talents of organizations can

- find their own solutions;

- develop their own skills;

- correct their behaviors and modify them;

- change their own attitudes;

- Access their own treasury of wisdom.

The necessary factor for the success of experts in the talent management of the staff is to know accurately the concept of talent and its related concepts. Therefore, here, short definitions of these concepts are presented:

Admeachel in his work in 2001 titled as war of talents has considered talent as a set of abilities of an individual. According to this definition, talent includes concepts such as intrinsic talent, skills, knowledge, intelligence, ability, instinct, and learning abilities and having talent of doing a field is mostly interpreted as a limit higher than the average of abilities (Gulnihal and Gumus, 2013).

Elements of talent are as follows:

- Aptitude: refers to intrinsic ability for doing affairs in situations which abilities originate from humans and they do not depend on environmental factors.

- Skills: refer to some part of ability to do work, and it is the result of learning and exercises. 
- Opportunity: opportunities are basically created in two ways:

a. Individuals search for an opportunity individually to indicate their talents and they achieve some successes in this way.

b. They are created via other individuals such as parents, professors, fellows, related experts, and managers.

\section{Barriers to the growth of talents}

In fact, a fair and gracious society is the one in which all individuals can be capable to pursue opportunities for presenting their talents. In the talent management system, unreal barriers which are based on organizational and relational pursues and hinder individuals' advances in spite of their qualifications are referred to as glass ceilings. Estean names two important cases of these barriers as sexism and racism and believes that we force others to throw away these discriminating believes and instead, he suggests a more rational way which causes that offenders eagerly stop discriminating actions. This important issue can be realized via indicating how they can have numerous profits for themselves and their organizations through removing discrimination and the use of the treasury of potential talents.

Rueat (2013) is another authors which investigated the glass ceiling. He pay specifically attention to the issue of sexism in his work published by International Work Organization and writes that women in all over the world have accessed higher levels of education and nowadays, more than $40 \%$ of workforce consists of women. But their shares of management positions are inappropriately low. The most important issue which should be considered in the definition of talent is that talent cannot be limited to a certain group, race, sex, or social class, but the chance of presenting talents may be very limited and the most social development of the $20^{\text {th }}$ century was due to the expansion of opportunities because situation, race, and sex were not barriers to presenting talents (Shayemi et al. 2013).

\section{The nature of talent management}

Armstrong (2012) defines talent management a set of coordinated activities for ensuring organizational attraction, retaining motivation, and developing talented individuals in organizations required for now and in the future and with considering this issue that talent is a great organizational resource (Armstrong, 2006: 390). Helen and Axelrod, in the book the war of talents, wrote that talents are defined as a set of abilities of an individual and introduced fighting for talents as a definitive way for getting talents. Accordingly, talent includes concepts such as personality, skill, knowledge, intelligence, judgment, experiencing abilities, tendencies, instinct, and also ability to learn. Talent consists of three elements of skills, abilities, and opportunities. The skill of the ability to do something in the best way which is the result of learning and exercising, the intrinsic ability to use specific skills or doing affairs in particular situations, and opportunity is the talent of presenting which per se requires an opportunity (Michel et al. 2001: 6).

In simple words, talent management ensures organizations that proficient individuals with appropriate skills are put in appropriate professional statuses for achieving expected 
objectives of business.

\section{Why nowadays have talent management been paid particular attention to?}

1. Direct relationship between talents and superior performance of organizations: studies indicate that when an organization invests on its organizations, it will have tremendous increase in its income. As a results, talents can have influences on the business performance.

2. The fiscal value of organizations depends on the quality of their talents and they increase the value of organizations as rapidly as possible.

3. Business in more complicated and dynamic environments in which serious competition has made long maintenance of competitive advantage more difficult. New products and models of business have shorter cycles and demand continuous innovation. Who should be forerunners of the encounter of organization with these challenges? Who can take the responsibility of leadership of organizations in this complicated and dynamic environment of business?

4. Changes in the staff's expectations: the staff's expectations are changing and increasingly interested in doing challenging jobs and demand changes in their career paths. Responding to numerous challenges has made seizing hearts and brains the staff of today. In addition, organizational culture is very determinative in attracting and maintaining key talents and via organizational culture, the staff will be interested in organizations and managers (Sayyadi et al. 2011: 83).

In fact, talent management includes a complete set of processes for identifying, applying and managing individuals are required for successful performance of the strategy of business. These processes effective on the life cycle of the staff are divided into the three main fields: attracting talents, making talents consistent and retaining them, and developing talents.

\section{Attracting talents}

This stage includes all issues related to identifying individuals with the set of high-level skills, for jobs needed by organizations. Accordingly, whom should organizations should invest on? How should human force be organized? How should one plan for employing in determined posts? What kinds of talents are required for organizational development? How is the main organizational plan designed? These questions are only a part of the questions which are considered as the most valuable organizational capitals in an organization in case of drawing the path of attracting and developing its own staff.

\section{Making talent consistent and retaining them}

When an organization was successful in completing the process of employing in desired posts, what is the next step? In this stage, it is necessary that the set of individuals' appropriate skills should be consistent in the same path with their professional tasks. In other words, the performance of workforce should be managed in order that organizations ensure that they are in a path where their human forces have the highest level of productivity. Another issue 
which should be considered in the process of retaining talents is the services compensation system. In addition that in organizations it is necessary that the policy of compensating fair services should be developed, it is necessary that the output of reports and analyses resulting from evaluating talents and performance of individuals should be considered in the system of calculating the staff's services compensation.

\section{Developing talents}

The final step in this process includes issue related to learning and developing talents. In this stage, the staff needs a clear and tangible path of professional development. In this case, organizations should have more investment on their staff for creating learning and development opportunities in order to retain their skills up to date in the line with responding expectations and future needs of organizations via this way (Megri, 2014).

\section{Advantages of applying the talent management system}

Why is the term talent management applied as a current concept in the organizational cycle? There is a good reason for this issue: this issue is beneficial at the same extent for both managers and business. As mentioned, talent management ensures this issue that each of the employees, with specific talents and skills, are placed in their appropriate jobs. In addition, the advantages of services compensation are fair. Additionally, their career paths are clear and act as increasing factors of motivation for better professional opportunities, both inside and outside organizations. Talent management provides processes and instruments appropriate for supporting and empowering mangers. Accordingly, they find out that what expectations they should have from their staff. This issue causes the improvement of working relations. As a result, organization with investing on talent management on the one hand can enjoy a high return of investment and on the other hand, a set of diverse talents will be created in organizations in such conditions, organizations can enjoy the advantages of adroit and motivated work forces (Tajuddin and Maali, 2008: 191).

\section{Centralized databases for talent management}

Centralized databases are powerful data which create the capability of centralized talent management and help that you can apply the most appropriate individuals in organizational roles. There is no difference that these individuals are both in and out of organizations, drawing the role of each of the candidates can create a common language which can determine the future needs (Shayemi et al. 2013).

\section{Effective stages in talent management}

An appropriate strategy in talent management has three components. In case of the existence of the talent management system, the first component includes the evaluation of current processes of the system in organizations. By doing an appropriate evaluation, the deficits and weaknesses of the system can be identified and some suggestions can be provided for eliminating them. The next process is to design and implement the talent system (an instrument or software system for supporting) which supports the process of designing and supervising, providing the results in the structure of the system, implementing and 
categorizing. The last component is related to accurate analysis of talents. Observation and supervision over the issue whether the identified talents are put in the appropriate places for doing an activity indicates that by implementing a smart strategy in business for making talent management effective can be researchable.

\section{Talent management in processes of human resource development}

This model is a conceptual framework which separates the questions related to the literature of talent management and strategic human resource management from each other. The framework starts with the output more interested by organizations, strategies and competitive advantages. Organizations enter the next stage according to the decision making in this stage and determine the strategic concepts related to talents. Then, resources of talents are identified, and in the next stage, according to the appropriate time and place of them, they are determined and classified in the line with strategies of their organizations. Then, the identified and classified talents should be developed. The next stage in this hierarchy is the talent management system which includes the following levels:

1. Selection

2. Employment

3. Performance management

4. Service compensation

Talent management has been defined as a system for identifying, employing, training, enhancing, and retaining talented individuals and with the aim of optimizing the power of organizations for realizing the results of business. Regarding the definition of talent management and considering the life cycle of the staff as a model for integration, the most important processes of human resource development, it can be understood that issues related to talent management can be established and developed in all processes of the cycle (Altinoz et al. 2013).

\section{Selecting and employing}

Selecting is a stage for accepting or rejecting the demands of clients and job applicants in such a way that the most appropriate and qualified and talented of them are selected and determined. There are different methods for selecting individuals. Some of the best cases of these methods are as follows:

- Structured interview

- Evaluation canon

- Socialization process

Nowadays, in the employment market, there is a severe competition for attracting superior talents. The most important issue is that the majority of your potential candidates are working in other places now. This issue complicates the attraction strategy because organization not only are faced with the lack of ready and accessible workforces, but in some of the industries, 
the possibility of employing candidates with high quality is not available with the traditional methods and systems. Resources and techniques of employment, in terms of needing active and passive applicants, are different. The best methods for accessing passive applicants are via reagents, exploration of databases, internet sites, local associations and networks, and organizational announcements. In addition, methods of accessing active applicants are via the list of job applicants, advertisements, holding fairs, job sites and searching in biological databases. However, to access active and passive applicants, planning is required.

\section{Active applicants versus passive ones}

Passive applicants are those individuals with particular performance which are a part of organizational competitive advantages they usually are not interested in spending a lot of time for finding new professional situations. Therefore, in addition to spending a lot of time for employing these individuals, another main difference of this group with active applicants is to create the necessity for organizations for realizing their expectations in terms of organizational advantages and culture. Organizations should create conditions and situations in which required motivation for passive applicants can be provided and their sections can be idea.

Active applicants can be found more easily and they themselves directly apply for organizational posts. Time is very short for attracting them and usually they are enthusiastic for doing interviews and evaluation processes. In this method, applicants can present their abilities to you (Sahai and Srivastava, 2012).

In spite of the fact that using resources of employment and traditional selection processes whose aims is to attract active applicants are simpler, this method cannot always be the best strategy. It seems that companies require approaches with tactics combined with methods of attraction of active and passive applicants.

\section{Developing a design for the employment plan}

The basis necessary for attracting talents is to develop a plan. What is your aim? What needs do you have for the next year? How turnover and available limitations influence your needs to resources and also identification and attraction of applicants in the next 12 months? In the same line, you should consider the current market of workforces, competition for attracting talents, the set of necessary specific skills and accessible applicants. After defining aims clearly, you can identify and determine those good resources which move you towards the best applicants in the most appropriate time.

Successful organizations establish a kind of clear interaction between the attraction plan and all fields related to it. They ensure that all relations are clear and integrated, different approaches are defined for each of the aims, proper follow-up methods are determined for each stage, timetables are developed for performing, and in each stage, necessary responses are provided.

To implement a successful strategy of attraction, understanding this issue that whom you need to attract and also having a plan for adding applicants to your employment list are 
necessary. It may be that these necessities can transform your available employment plans as easily as possible.

However, the complicatedness of the process of attracting talents can be very cumbersome and difficult, but finding companies providing professional services to the staff and creating strategic companies can be an approach for applying successful strategies of attracting talents in employment plans and implementing related processes. Do you expect that for your future employment needs, you can have sufficient resources? Does the current employment process move successfully you towards active and passive applicants? From now on, try to assign some time to be ensured that you have an appropriate and proper project for attracting and having continuous relationship with required applicant in the future. (Maali, 2008: 198).

\section{2. learning and training management}

The need to organizational learning has been significantly approved nowadays. Conducted longitudinal researches indicating the positive relationship between investment on learning and the income of shareholders, according to the report of ASTD in 2006, those companies which have more investment on learning and can sooner and better learn from their own competitors, have had satisfaction of the staff and clients, quality of products and services, productivity, income, and in general, higher profits. Talent is something whose general profile is potentially available in all creatures, but the activity of finding it depends on the achievement of appropriate chance. In addition, training is a proper instrument for growing and developing talents in such a way that in a definition of education, it refers to as rearing, or an activity in realizing the potential talents of an individual. One of the approaches in the structure of human resources is that internal talents of organizations are identified and are put in the process of education. Each organization, dependent on their conditions and facilities, apply different strategies for education. Some of the organizations, wholly or in part, outsource the process of education. Some of the organizations use different method such as holding courses, using electronic training, and virtual classes or a combination of them.

\section{Performance management}

In the study of literature of organizations which apply plans of performance management, are referred to as organizations with superior performance. In fact, effective performance management as the key leverage of change for increasing the mentioned team and individual achievements. The main component of the performance management system is performance evaluation. But, evaluation is the prerequisite for each effective performance management plan. In effective performance management, along with performance management, there are activities such as training, successor training, payment based on performance, etc. but evaluation is the prerequisite to each effective performance management plan. One of the main objectives of performance evaluation is development and empowerment of human resources. To achieve this necessary result which the result of performance achievement is one of the important resources of identifying individuals' and organizations' educational needs, if a system of the staff's performance evaluation is considered as effective, the staff will know it useful and in such a condition, rewards can be efficient. In such conditions, in addition to creating motivation among the staff, managers conclude that rewards cause the 
increase in not only efficiency, but also the satisfaction of the staff.

\section{Paying based on performance}

An appropriate approach for paying the staff is that the basis for paying them depends their performance with a particular emphasis on the output and income of an organization. In addition, this issue is important that you have a view to both the amount of payment in the market and competitors. Accordingly, you can have an analysis on the gap between the payment of the organization, market, and competitors. When employees feel that what they receive from organizations is less that their real value, they are highly tended to leave organizations.

In paying based on performance, the following issues should be considered:

1. To determine what an individuals should receive according to his performance for the clearly defined objectives.

2. To calculate the difference between payments based on objectives and current payments.

3. To allocate budget for paying based on objectives.

4. To apply plans of varied payments for extraordinary objectives based on performance.

5. To consider knowledge, skills, and experience as factors for more payments.

The enhancement in the wages of the staff is when they achieve new skills (with considering this issue that these skills depend on the output of organizations).

\section{Successor training}

Managers of organizations should know talent identification and successor training as their main tasks. Implementing the plans of talent identification and successor training whose main objectives are to find management talents of organizations should not hinder the educational investment on the staff in spite of the lack of talents for taking the responsibility of management posts, they can create values in their jobs. Organizations, to solve the crisis of talents, should focus on the inside of organizations and adopt successor training strategies which concentrate on development and training of their available talents. Historically, the most successful organizations in performance are those which have long-term investment on their staff. By investing on the time and costs for developing internal talents, these organizations are capable to pass this stage in case that their main talents are retired or leave organization for every reason (Seyyedi, 2012: 149).

Adopting the strategy of winner-winner successor training management allows organizations to identify key jobs, potential successors, and skill gaps and provide available professional alternatives and instruments for planning and access to their career objectives. Applying a comprehensive and coordinated approach can optimize the advantages created for the staff managers and organizations. It has been proved that successor training plans which are intertwined with individuals' career paths increase the spirit of the staff and their productivity. 
Organizations which support job development, with allowing the staff to find new opportunities in organizations and motivating occupational mobility, probably share them in their job development (Tajuddin, 2009: 209).

Since these employees most probably search opportunities in organizations; therefore, the process of maintaining can be shaped as properly as possible. In general, this issue results in increasing the staff's satisfaction. However, in general, we pursue a new kind of successor training management strategy, but recent studies of the human resources management associations indicate that more than $70 \%$ of the studied organizations are lacking in successor training strategies. Nowadays, this issue has a particular significance because for the first time, in the new world of business, organizations have endured a lot of significant losses due to losing their experienced forces and this issue has been concurrent with the lack of human forces with required skills for succession and employment so that the Bureau of Laborof the USA has predicted that up to 2010 , about 168 million job opportunities will be provided, this is while workforces will be only 158 million chances. Therefore, we will face with the lack of 10 million workforces. The degree of demand for proficient staff is much more than the degree of supply. This issue can press some organizations in industrial fields more than others in such a way that nowadays, fields such as production, engineering and technology, information technology, power and water, energy and transportation, and etc. have encountered with skillful workforces (MaaliTafti and Tajyuddin, 2008: 199).

\section{Conclusion}

Nowadays, organizations have well found out that to be successful in the global complicated economy and also survive in the competitive environment of business, having the best talents is required. Concurrent to understanding the need to employment, development and maintenance of talents, organizations have found out that talents are critical resources which require management for accessing the best results. In 60's to 70's, talent management has been considered as a partial responsibility and it was burdened on the shoulder of personnel departments, while nowadays, talent management is an organization task whose responsibility is burdened on the shoulder all departments and is considered more serious than ever. Doubtlessly, the present age is the age of organizations and the authorities of these organizations are human beings who can produce advancement, movement, and development in organizations as a result of having the most tremendous resources of power, i.e. thought. In recent years, in Iranian organizations, the issue of training and developing human resources in different forms such as identifying and training talents, training successors, future managers, shadow managers, and etc. have been considered. The role of talent management in increasing productivity of human resource management and maintaining the competitive power in complicated and dynamic environments are vital. Talent management should be institutionalized as a system flowing in the processes of human resources. In fact, talent management belongs to all processes of human resources development. Talent identification $f$ human resources will causes that organizations utilize adroit and motivated workforces which this issue will result in increasing in organizational productivity. As a result, it is obvious that talent management constructs the main core of human resource management and main factor of organizational success. In addition, the department of human resources is responsible for 


\section{I Macrothink}

creating talent pools and managers are the heirs of these talent pools.

\section{Resources}

Ahmadi, A. et al. (2012). The role of social capital on the improvement of talent management in the Physical Education Organization. Journal of Studies on Sports Management. No. 13. Spring. Pp. 260-267.

Tajuddin, M. and MaaliTafti, M. (2008). Talent management in human resource management processes. Tadbir. 20 (202). Pp. 72-73.

Tajuddin, M. (2008). Payment system based on performance. Tadbir. 19 (200).

Tajuddin, M. and Maali, Tafti, M. (2008). Why talent management? Tadbir. No. 191. Pp. 62-63.

Hosseini, A. (2011). The role of talent management in supplying and keeping talented human resources. Journal of Modern Economy and Commerce. No 23 and 24. Pp. 190-205.

Khaluvandi, F. and Abbaspour, A. (2013). Developing the optimization model of the talent management process; case study of Pars Oil and Gas Company. General Management Research. $6^{\text {th }}$ year. 19 .

Rezaeian, A. and Soltani, F. (2009). Introducing a comprehensive and systemic model of talent management for improving personal performance of the staff working in the Oil Industry. Journal of Management and Human Resources in the Oil Company. Pp.7-50.

Seyyedi, A. (2012). Talent management in human resources development processes. Monthly of Work and Society. No. 149. Pp. 12-18.

Shayemi, A. et al. (2013). Talent management strategy and its relationship with emotional intelligence of the staff. Journal of Management Studies (Improvement and Evolution). Year 22. No. 70. Pp. 40-70.

Sayyadi, S., Mohammadi, M. and Nikpour, A. (2011). Talent management as a key concept in organizational domain. Monthly of Work and Society. No 135. P. 81-86.

MaaliTafti, M. and Tajuddin, M. (2008). Successor training as the key for saving in talent crisis. Tadbir. Year 19. No. 199. Pp. 66-67.

MaaliTafti, M. and Tajuddin, M. (2008). Attracting talents in a competitive market. Tadbir. Year 19. No. 198. Pp. 74-75. 